УДК 539.3, 531.3, 001.891.573

\title{
Models of Deformation of Stiffened Orthotropic Shells under Dynamic Loading
}

\author{
Alexey A. Semenov* \\ Saint Petersburg State University of Architecture and Civil Engineering \\ 2nd Krasnoarmeyskaya, 4, Saint Petersburg, 190005
}

Russia

Received 23.03.2016, received in revised form 02.08.2016, accepted 08.09.2016

Two models of deformation of reinforced orthotropic shells under dynamic loading are considered in this paper. One such model is in the form of equations of motion and another model is in the form of a system of ordinary differential equations. Mathematical models are based on the hypotheses of the KirchhoffLove theory of shells. They take into account the geometric nonlinearity, orthotropic material properties and reinforcement elements. All relations of the models are in general form, and they can be used for a wide range of structures (shallow shells of double curvature, cylindrical, conical, spherical and toroidal shells and panels, etc.). An important feature of the proposed model is the ability to introduce stiffeners both discretely and by the method of constructive anisotropy (MCA) in accordance with their shear and torsional rigidity. The second model is derived by applying the Kantorovich method to the functional of the total energy of deformation of a shell. The resulting initial value problem is easier to solve than the system of equations of motion in partial derivatives.

Keywords: mathematical model, shell, dynamic loading, orthotropy, geometric nonlinearity, the equations of motion, method of constructive anisotropy.

DOI: 10.17516/1997-1397-2016-9-4-485-497.

\section{Introduction}

Since 40-ies the intensive development of the theory of shells has begun in connection with the technological demand. During the first three decades researchers dealt mainly with static problems in the theory of thin plates and shells. Since the 70s of the last century the emphasis in studies of plates and shells is shifted to dynamic problems. Above all, this is due to demands of the aviation and space technology. However, the study of the dynamic behaviour of structures is also essential for shipbuilding and civil engineering.

The most studied is the behaviour of single-layer isotropic shell structures under dynamic loading. In the last decade, structures fabricated of composite materials are of great interest. For example, such materials as carbon fibre reinforced epoxy resin, graphite-fiber reinforced and boron-fiber reinforced plastics are widely used. The behavior of shells fabricated of these materials has been insufficiently studied [1-12].

The main objectives of the study of shell structures under dynamic loading are to investigate their stability, strength and vibrations as evidenced by review articles and monographs [13-23].

*sw.semenov@gmail.com

(c) Siberian Federal University. All rights reserved 
One should mention the extensive review article of E. A. Kogan and A.A. Yurchenko [13] which is devoted to free and forced nonlinear oscillations of multilayered thin elastic plates and shells under periodic loading.

Most studies are devoted to the vibration of isotropic structures [1, 4, 7, 8, 12, 24-30].

As for geometry of structures, the vast majority of studies are devoted to closed cylindrical shells $[4,5,7,11,26,27,30-32]$ because it is connected with the solution of a number of very important practical problems, for example, the occurrence of dynamic periodic load caused by the internal fluid flow. Such problems can be considered as axially symmetric. Studies on conic $[3,24]$ and the spherical $[28,33]$ closed shells have received little attention. Non-axisymmetric problems for closed shells [34] are also rarely addressed, although they are important in studying structures with form imperfections.

Thus, the study of strength, stability and nonlinear oscillations of reinforced orthotropic shells of revolution under dynamic loading is a vital issue.

The aim of this work is to construct a mathematical model of deformation of reinforced orthotropic shells under dynamic loading.

\section{Mathematical models of deformation of reinforced orthotropic shells under dynamic loading}

We consider an orthotropic shell supported by the ribs on the internal side of the shell. It is subjected to the influence of an external uniformly distributed lateral load $q=q(x, y, t)$.

To form relations of mathematical model we first consider the expressions for the forces and moments. The unknowns are three displacement functions $U=U(x, y, t), V=V(x, y, t), W=$ $W(x, y, t)$. Using the Kirchhoff - Love model for orthotropic shells, we have

$$
\begin{gathered}
N_{x}=\frac{E_{1}}{1-\mu_{12} \mu_{21}}\left[\left(h+F_{x}\right)\left(\varepsilon_{x}+\mu_{21} \varepsilon_{y}\right)+S_{x}\left(\chi_{1}+\mu_{21} \chi_{2}\right)\right], \\
N_{y}=\frac{E_{2}}{1-\mu_{12} \mu_{21}}\left[\left(h+F_{y}\right)\left(\varepsilon_{y}+\mu_{12} \varepsilon_{x}\right)+S_{y}\left(\chi_{2}+\mu_{12} \chi_{1}\right)\right], \\
N_{x y}=G_{12}\left[\left(h+F_{y}\right) \gamma_{x y}+2 S_{y} \chi_{12}\right], \quad N_{y x}=G_{12}\left[\left(h+F_{x}\right) \gamma_{x y}+2 S_{x} \chi_{12}\right], \\
M_{x}=\frac{E_{1}}{1-\mu_{12} \mu_{21}}\left[S_{x}\left(\varepsilon_{x}+\mu_{21} \varepsilon_{y}\right)+\left(\frac{h^{3}}{12}+J_{x}\right)\left(\chi_{1}+\mu_{21} \chi_{2}\right)\right], \\
M_{y}=\frac{E_{2}}{1-\mu_{12} \mu_{21}}\left[S_{y}\left(\varepsilon_{y}+\mu_{12} \varepsilon_{x}\right)+\left(\frac{h^{3}}{12}+J_{y}\right)\left(\chi_{2}+\mu_{12} \chi_{1}\right)\right], \\
M_{x y}=G_{12}\left[S_{y} \gamma_{x y}+2\left(\frac{h^{3}}{12}+J_{y}\right) \chi_{12}\right], \quad M_{y x}=G_{12}\left[S_{x} \gamma_{x y}+2\left(\frac{h^{3}}{12}+J_{x}\right) \chi_{12}\right],
\end{gathered}
$$

where $h$ is thickness of the shell; $E_{1}, E_{2}$ are elastic moduli; $G_{12}$ is the shear modulus; $\mu_{12}, \mu_{21}$ is the Poisson's ratio; $F_{x}, F_{y}, S_{x}, S_{y}, J_{x}, J_{y}$ are ribs characteristics which are described below; $\varepsilon_{x}, \varepsilon_{y}, \gamma_{x y}$ are strains that account for the geometric nonlinearity; $\chi_{1}, \chi_{2}, \chi_{12}$ are curvature and torsion functions of the form

$\chi_{1}=\frac{1}{A} \frac{\partial \theta_{1}}{\partial x}+\frac{1}{A B} \frac{\partial A}{\partial y} \theta_{2}, \chi_{2}=\frac{1}{B} \frac{\partial \theta_{2}}{\partial y}+\frac{1}{A B} \frac{\partial B}{\partial x} \theta_{1}, 2 \chi_{12}=\frac{1}{A} \frac{\partial \theta_{2}}{\partial x}+\frac{1}{B} \frac{\partial \theta_{1}}{\partial y}-\frac{1}{A B}\left(\frac{\partial A}{\partial y} \theta_{1}+\frac{\partial B}{\partial x} \theta_{2}\right)$,

where $\theta_{1}=-\frac{1}{A} \frac{\partial W}{\partial x}, \theta_{2}=-\frac{1}{B} \frac{\partial W}{\partial y}$ and $A, B$ are Lame parameters. 
Stiffeners can be introduced with the use of the method of constructive anisotropy [35] or discretely. When using the method of constructive anisotropy, we have

$$
\begin{aligned}
& F_{x}=\sum_{i=1}^{n} \frac{h^{i} r_{i}}{\tilde{b}}+\sum_{j=1}^{m}\left(\frac{h^{j} r_{j}}{\tilde{a}}-\sum_{i=1}^{n} \frac{h^{i j} r_{i} r_{j}}{\tilde{a} \tilde{b}}\right) \frac{r_{j}}{\tilde{a}} ; \quad F_{y}=\sum_{j=1}^{m} \frac{h^{j} r_{j}}{\tilde{a}}+\sum_{i=1}^{n}\left(\frac{h^{i} r_{i}}{\tilde{b}}-\sum_{j=1}^{m} \frac{h^{i j} r_{i} r_{j}}{\tilde{a} \tilde{b}}\right) \frac{r_{i}}{\tilde{b}} ; \\
& S_{x}=\sum_{i=1}^{n} \frac{S^{i} r_{i}}{\tilde{b}}+\sum_{j=1}^{m}\left(\frac{S^{j} r_{j}}{\tilde{a}}-\sum_{i=1}^{n} \frac{S^{i j} r_{i} r_{j}}{\tilde{a} \tilde{b}}\right) \frac{r_{j}}{\tilde{a}} ; \quad S_{y}=\sum_{j=1}^{m} \frac{S^{j} r_{j}}{\tilde{a}}+\sum_{i=1}^{n}\left(\frac{S^{i} r_{i}}{\tilde{b}}-\sum_{j=1}^{m} \frac{S^{i j} r_{i} r_{j}}{\tilde{a} \tilde{b}}\right) \frac{r_{i}}{\tilde{b}} ; \\
& J_{x}=\sum_{i=1}^{n} \frac{J^{i} r_{i}}{\tilde{b}}+\sum_{j=1}^{m}\left(\frac{J^{j} r_{j}}{\tilde{a}}-\sum_{i=1}^{n} \frac{J^{i j} r_{i} r_{j}}{\tilde{a} \tilde{b}}\right) \frac{r_{j}}{\tilde{a}} ; \quad J_{y}=\sum_{j=1}^{m} \frac{J^{j} r_{j}}{\tilde{a}}+\sum_{i=1}^{n}\left(\frac{J^{i} r_{i}}{\tilde{b}}-\sum_{j=1}^{m} \frac{J^{i j} r_{i} r_{j}}{\tilde{a} \tilde{b}}\right) \frac{r_{i}}{\tilde{b}} ; \\
& F_{p}=\sum_{i=1}^{n} \frac{h^{i} r_{i}}{\tilde{b}}+\sum_{j=1}^{m} \frac{h^{j} r_{j}}{\tilde{a}}-\sum_{i=1}^{n} \frac{h^{i j} r_{i} r_{j}}{\tilde{a} \tilde{b}}, \quad \tilde{a}=\left(a-a_{1}\right) A, \quad \tilde{b}=b B\left(\frac{a-a_{1}}{2}\right),
\end{aligned}
$$

where $h^{i}$ is the rib height; indexes $i$ and $j$ indicate the number of rib located parallel to the $x$ and $y$ axis, respectively; $n, m$ are numbers of ribs; $h^{i j}=\min \left\{h^{i}, h^{j}\right\} ; r$ is the rib width; $a, b$ are limit values along $x, y$ axes; $a_{1}$ is the offset from the origin along the $x$ axis;

$$
\begin{gathered}
S^{i}=\frac{h^{i}\left(h+h^{i}\right)}{2}, S^{j}=\frac{h^{j}\left(h+h^{j}\right)}{2}, S^{i j}=\frac{h^{i j}\left(h+h^{i j}\right)}{2}, J^{i}=0.25 h^{2} h^{i}+0.5 h\left(h^{i}\right)^{2}+\frac{1}{3}\left(h^{i}\right)^{3}, \\
J^{j}=0.25 h^{2} h^{j}+0.5 h\left(h^{j}\right)^{2}+\frac{1}{3}\left(h^{j}\right)^{3}, \quad J^{i j}=0.25 h^{2} h^{i j}+0.5 h\left(h^{i j}\right)^{2}+\frac{1}{3}\left(h^{i j}\right)^{3} .
\end{gathered}
$$

The method of constructive anisotropy can be used if the ratio of distance between ribs to shell length is not more than 0.1 .

When ribs are introduced discretely, we have

$$
\begin{aligned}
& F_{x}=F_{y}=F_{p}=\sum_{j=1}^{m} h^{j} \bar{\delta}\left(x-x_{j}\right)+\sum_{i=1}^{n} h^{i} \bar{\delta}\left(y-y_{i}\right)-\sum_{i=1}^{n} \sum_{j=1}^{m} h^{i j} \bar{\delta}\left(x-x_{j}\right) \bar{\delta}\left(y-y_{i}\right), \\
& S_{x}=S_{y}=\sum_{j=1}^{m} S^{j} \bar{\delta}\left(x-x_{j}\right)+\sum_{i=1}^{n} S^{i} \bar{\delta}\left(y-y_{i}\right)-\sum_{i=1}^{n} \sum_{j=1}^{m} S^{i j} \bar{\delta}\left(x-x_{j}\right) \bar{\delta}\left(y-y_{i}\right), \\
& J_{x}=J_{y}=\sum_{j=1}^{m} J^{j} \bar{\delta}\left(x-x_{j}\right)+\sum_{i=1}^{n} J^{i} \bar{\delta}\left(y-y_{i}\right)-\sum_{i=1}^{n} \sum_{j=1}^{m} J^{i j} \bar{\delta}\left(x-x_{j}\right) \bar{\delta}\left(y-y_{i}\right),
\end{aligned}
$$

where $\bar{\delta}\left(x-x_{j}\right)$ and $\bar{\delta}\left(y-y_{i}\right)$ are differences of two Heaviside functions: $\bar{\delta}\left(x-x_{j}\right)=$ $U\left(x-a_{j}\right)-U\left(x-b_{j}\right) ; \bar{\delta}\left(y-y_{i}\right)=U\left(y-c_{i}\right)-U\left(y-d_{i}\right)$, where $a_{j}=x_{j}-r_{j} / 2, b_{j}=$ $x_{j}+r_{j} / 2, c_{i}=y_{i}-r_{i} / 2, d_{i}=y_{i}+r_{i} / 2$.

In the presence of reinforcement, rib thickness is defined as

$$
H(x, y)=\sum_{j=1}^{m} h^{j} \bar{\delta}\left(x-x_{j}\right)+\sum_{i=1}^{n} h^{i} \bar{\delta}\left(y-y_{i}\right)-\sum_{i=1}^{n} \sum_{j=1}^{m} h^{i j} \bar{\delta}\left(x-x_{j}\right) \bar{\delta}\left(y-y_{i}\right)
$$

then the thickness of the entire structure is $h+H$.

The total deformation energy functional of the shell under dynamic loading is

$$
I=\int_{t_{0}}^{t_{1}}\left(K-E_{p}\right) d t
$$


where $K$ is the kinetic energy of deformation; $E_{p}=\Pi-\mathrm{A}$ is the difference of potential energy of deformation of the system and the work of external forces that corresponds to the functional of the static problem; $t$ is time.

The kinetic energy of deformation of reinforced shell has the form $[35,36]$

$$
K=\frac{\rho}{2} \int_{a_{1}}^{a} \int_{0}^{b} \int_{-h / 2}^{h / 2+H}\left[\left(\frac{\partial U}{\partial t}\right)^{2}+\left(\frac{\partial V}{\partial t}\right)^{2}+\left(\frac{\partial W}{\partial t}\right)^{2}\right] A B d x d y d z,
$$

where $\rho=\frac{\gamma}{g}$ ( $\gamma, g$ are the specific gravity of the shell material and the gravity acceleration).

Upon integrating (3) with respect to $z$, we obtain

$$
K=\frac{\rho}{2} \int_{a_{1}}^{a} \int_{0}^{b}\left\{\left(h+F_{p}\right)\left[\left(\frac{\partial U}{\partial t}\right)^{2}+\left(\frac{\partial V}{\partial t}\right)^{2}+\left(\frac{\partial W}{\partial t}\right)^{2}\right]\right\} A B d x d y .
$$

Next, we consider two models. First model is in the form of equations of motion and second model is in the form of a system of ordinary differential equations.

\subsection{Equations of motion}

Since the behavior of the system in the time interval $\left[t_{0}, t_{1}\right]$ must satisfy the condition [36]

$$
\delta \int_{t_{0}}^{t_{1}}(K-\Pi+\mathrm{A}) d t=0
$$

we seek the first variation of functional (2), and then we set it equal to zero. First, we find the variation of the kinetic energy

$\delta \int_{t_{0}}^{t_{1}} K d t=\frac{\rho}{2} \int_{t_{0}}^{t_{1}} \int_{a_{1}}^{a} \int_{0}^{b}\left(h+F_{p}\right)\left[2 \frac{\partial U}{\partial t} \delta\left(\frac{\partial U}{\partial t}\right)+2 \frac{\partial V}{\partial t} \delta\left(\frac{\partial V}{\partial t}\right)+2 \frac{\partial W}{\partial t} \delta\left(\frac{\partial W}{\partial t}\right)\right] A B d x d y d t$.

One should change this expression such that there are no variations of the time derivatives of the unknown functions $U(x, y, t), V(x, y, t), W(x, y, t)$ with respect to $t$ under the integral sign. Upon integrating by parts, we obtain

$$
\begin{gathered}
\delta \int_{t_{0}}^{t_{1}} K d t=-\rho \int_{t_{0}}^{t_{1}} \int_{a_{1}}^{a} \int_{0}^{b}\left(h+F_{p}\right)\left[\frac{\partial^{2} U}{\partial t^{2}} \delta U+\frac{\partial^{2} V}{\partial t^{2}} \delta V+\frac{\partial^{2} W}{\partial t^{2}} \delta W\right] A B d x d y d t+ \\
+\left.\rho \int_{a_{1}}^{a} \int_{0}^{b}\left\{\left(h+F_{p}\right)\left[\frac{\partial U}{\partial t} \delta U+\frac{\partial V}{\partial t} \delta V+\frac{\partial W}{\partial t} \delta W\right]\right\}\right|_{t=t_{0}} ^{t=t_{1}} A B d x d y .
\end{gathered}
$$

The second term in this equation allows us to formulate initial conditions, specifically, either all functions are equal to zero or first derivatives of these functions are equal to zero at the initial moment of time.

The first term in this expression, from which the equations of motion are formed (or rather, the inertial terms of these equations) can be reduced to the form

$$
-\rho \int_{t_{0}}^{t_{1}} \int_{a_{1}}^{a} \int_{0}^{b}\left\{\left(h+F_{p}\right) \frac{\partial^{2} U}{\partial t^{2}} \delta U+\left(h+F_{p}\right) \frac{\partial^{2} V}{\partial t^{2}} \delta V+\left(h+F_{p}\right) \frac{\partial^{2} W}{\partial t^{2}} \delta W\right\} A B d x d y d t .
$$


Since potential energy $E_{p}$ does not depend on derivatives of the unknown functions with respect to $t$, we have $\delta \int_{t_{0}}^{t_{1}} E_{p} d t=\int_{t_{0}}^{t_{1}} \delta E_{p} d t$. Taking into account (1), functional $E_{p}$ has the form $[35]$

$$
\begin{aligned}
E_{p}=\frac{1}{2} \int_{a_{1}}^{a} \int_{0}^{b}\{ & N_{x} \varepsilon_{x}+N_{y} \varepsilon_{y}+\frac{1}{2}\left(N_{x y}+N_{y x}\right) \gamma_{x y}+M_{x} \chi_{1}+M_{y} \chi_{2}+ \\
& \left.+\left(M_{x y}+M_{y x}\right) \chi_{12}-2 q W\right\} A B d x d y .
\end{aligned}
$$

Let us find the first variation of this functional and set it equal to zero. Then we carry out transformation in order to exclude derivatives of displacements under the variation sign. As a result, we obtain

$$
\begin{gathered}
-\int_{a_{1}}^{a} \int_{0}^{b}\left\{\left[\frac{\partial B N_{x}}{\partial x}-N_{y} \frac{\partial B}{\partial x}+\frac{\partial A N_{x y}}{\partial y}+\frac{\partial A}{\partial y} N_{x y}\right] \delta U+\left[\frac{\partial A N_{y}}{\partial y}+\frac{\partial B N_{x y}}{\partial x}+N_{x y} \frac{\partial B}{\partial x}-\right.\right. \\
\left.-\frac{\partial A}{\partial y} N_{x}\right] \delta V+\left[A B\left(k_{x} N_{x}+k_{y} N_{y}\right)+\frac{\partial}{\partial x}\left(\frac{B}{A} \frac{\partial W}{\partial x} N_{x}\right)+\frac{\partial}{\partial y}\left(\frac{A}{B} \frac{\partial W}{\partial y} N_{y}\right)+\frac{\partial}{\partial y}\left(\frac{\partial W}{\partial x} N_{x y}\right)+\right. \\
+\frac{\partial}{\partial x}\left(\frac{\partial W}{\partial y} N_{x y}\right)+\frac{\partial^{2}}{\partial x^{2}}\left(\frac{B}{A} M_{x}\right)+\frac{\partial^{2}}{\partial y^{2}}\left(\frac{A}{B} M_{y}\right)+2 \frac{\partial^{2} M_{x y}}{\partial x \partial y}-\frac{\partial}{\partial x}\left(\frac{1}{A} \frac{\partial B}{\partial x} M_{y}\right)- \\
+\int_{a_{1}}^{a}\left\{A N_{x y} \delta U+A N_{y} \delta V+\left[\frac{\partial}{\partial y} \frac{\partial W}{\partial y} N_{y}+\frac{\partial W}{\partial x} N_{x y}-\frac{1}{B} \frac{\partial A}{\partial y} M_{x}+\frac{\partial}{\partial y}\left(\frac{A}{B} M_{y}\right)+\frac{\partial M_{x y}}{\partial x}\right] \delta W-\right. \\
\left.-M_{x y} \delta\left(\frac{\partial W}{\partial x}\right)-\frac{A}{B} M_{y} \delta\left(\frac{\partial W}{\partial y}\right)\right\}\left.\right|_{y=0} ^{y=b} d x+ \\
+\int_{0}^{b}\left\{B N_{x} \delta U+B N_{x y} \delta V+\left[\frac{B}{A} \frac{\partial W}{\partial x} N_{x}+\frac{\partial W}{\partial y} N_{x y}-\frac{1}{A} \frac{\partial B}{\partial x} M_{y}+\frac{\partial}{\partial x}\left(\frac{B}{A} M_{x}\right)+\frac{\partial M_{x y}}{\partial y}\right] \delta W-\right. \\
\left.-\frac{B}{A} M_{x} \delta\left(\frac{\partial W}{\partial x}\right)-M_{x y} \delta\left(\frac{\partial W}{\partial y}\right)\right\}\left.\right|_{x=a_{1}} ^{x=a} d y=0 .
\end{gathered}
$$

Neglecting transverse shear and rotational inertia, the equations of motion for orthotropic reinforced shells take the form

$$
\begin{gathered}
\rho\left[(h+\bar{F}) \frac{\partial^{2} U}{\partial t^{2}}\right] A B=\frac{\partial B N_{x}}{\partial x}-N_{y} \frac{\partial B}{\partial x}+\frac{\partial A}{\partial y} N_{x y}+\frac{\partial A N_{x y}}{\partial y} \\
\rho\left[(h+\bar{F}) \frac{\partial^{2} V}{\partial t^{2}}\right] A B=\frac{\partial A N_{y}}{\partial y}+\frac{\partial B N_{x y}}{\partial x}+N_{x y} \frac{\partial B}{\partial x}-\frac{\partial A}{\partial y} N_{x} \\
\rho(h+\bar{F}) \frac{\partial^{2} W}{\partial t^{2}} A B=A B\left(k_{x} N_{x}+k_{y} N_{y}\right)+\frac{\partial}{\partial x}\left(\frac{B}{A} \frac{\partial W}{\partial x} N_{x}\right)+\frac{\partial}{\partial y}\left(\frac{A}{B} \frac{\partial W}{\partial y} N_{y}\right)+ \\
+\frac{\partial}{\partial y}\left(\frac{\partial W}{\partial x} N_{x y}\right)+\frac{\partial}{\partial x}\left(\frac{\partial W}{\partial y} N_{x y}\right)+\frac{\partial^{2}}{\partial x^{2}}\left(\frac{B}{A} M_{x}\right)+\frac{\partial^{2}}{\partial y^{2}}\left(\frac{A}{B} M_{y}\right)+ \\
\quad+2 \frac{\partial^{2} M_{x y}}{\partial x \partial y}-\frac{\partial}{\partial x}\left(\frac{1}{A} \frac{\partial B}{\partial x} M_{y}\right)-\frac{\partial}{\partial y}\left(\frac{1}{B} \frac{\partial A}{\partial y} M_{x}\right)+A B q .
\end{gathered}
$$

System (6) is a system of differential equations in partial derivatives. Solution of this system presents difficulties. 


\subsection{Initial value problem for the ODE system}

In what follows we obtain the initial value problem for the system of ordinary differential equations using the Kantorovich method [37] to transform three-dimensional functional of the total energy of deformation of the shell into the one-dimensional functional.

First, we introduce dimensionless parameters

$$
\begin{gathered}
\xi=\frac{x-a_{1}}{a-a_{1}}, \eta=\frac{y}{b}, \bar{\lambda}=\frac{a A}{b B}, k_{\xi}=h k_{x}, \quad k_{\eta}=h k_{y}, \quad \bar{U}=\frac{a U A}{h^{2}}, \quad \bar{V}=\frac{b V B}{h^{2}}, \quad \bar{W}=\frac{W}{h} \\
\bar{F}_{p}=\frac{F_{p}}{h}, \quad \bar{t}=\frac{h}{a^{2} A^{2}} \sqrt{\frac{E_{1}}{\left(1-\mu_{12} \mu_{21}\right) \rho}} \cdot t, \quad \bar{P}=\frac{a^{4} A^{4} q}{h^{4} E_{1}}, \quad \bar{A}=\frac{a A}{h}, \quad \bar{B}=\frac{b B}{h}, \quad \bar{z}=\frac{z}{h} .
\end{gathered}
$$

Upon substituting these parameters into (2), we obtain

$$
\bar{I}=\int_{\bar{t}_{0}}^{\bar{t}_{1}}\left(\bar{K}-\bar{E}_{p}\right) d \bar{t}, \quad \text { where } \quad \bar{K}=\frac{2\left(1-\mu_{12} \mu_{21}\right) a^{4} A^{4}}{E_{1} h^{7}} K, \quad \bar{E}_{p}=\frac{2\left(1-\mu_{12} \mu_{21}\right) a^{4} A^{4}}{E_{1} h^{7}} E_{p},
$$

and

$$
\bar{K}=\frac{1}{\bar{A}^{2}} \int_{0}^{1} \int_{0}^{1}\left(1+\bar{F}_{p}\right)\left[\left(\frac{\partial \bar{U}}{\partial \bar{t}}\right)^{2}+\bar{\lambda}^{2}\left(\frac{\partial \bar{V}}{\partial \bar{t}}\right)^{2}+\bar{A}^{2}\left(\frac{\partial \bar{W}}{\partial \bar{t}}\right)^{2}\right] \bar{A} \bar{B} d \xi d \eta .
$$

This procedure was considered in details in [38].

Functional $\bar{I}$ can be expressed as

$$
\bar{I}=\int_{\bar{t}_{0}}^{\bar{t}_{1}} \int_{0}^{1} \int_{0}^{1}\left[\tilde{\Phi}_{1}(\dot{\bar{U}}, \dot{\bar{V}}, \dot{\bar{W}})-\tilde{\Phi}_{2}(\bar{U}, \bar{V}, \bar{W})\right] \bar{A} \bar{B} d \xi d \eta d \bar{t}
$$

Here $\tilde{\Phi}_{1}$ corresponds to $\bar{K}, \tilde{\Phi}_{2}$ corresponds to $\bar{E}_{p}$. The dot indicates derivative with respect to time.

According to the Kantorovich method, unknown functions can be represented as

$$
\bar{U}=\sum_{i=1}^{N} U_{i}(t) X 1(\xi) Y 1(\eta), \quad \bar{V}=\sum_{i=1}^{N} V_{i}(t) X 2(\xi) Y 2(\eta), \quad \bar{W}=\sum_{i=1}^{N} W_{i}(t) X 3(\xi) Y 3(\eta),
$$

where $U_{i}(t), V_{i}, W_{i}(t)$ are unknown functions, and all other functions are known. Examples of such functions for various boundary conditions are shown in Tab. 1 and variables $l=1, \ldots, \sqrt{N}, p=1, \ldots, \sqrt{N}$.

Table 1. Approximating functions for various boundary conditions

\begin{tabular}{|l|l|l|l|}
\hline Type of boundary condition & \multicolumn{1}{|c|}{ Function } & At $\xi=0, \xi=1$ & At $\eta=0, \eta=1$ \\
\hline Simple support & $\bar{U}(\xi, \eta), \bar{V}(\xi, \eta), \bar{W}(\xi, \eta)$ & $\sin (p \pi \xi)$ & $\sin (l \pi \eta)$ \\
\hline Clamp & $\bar{U}(\xi, \eta), V(\xi, \eta)$ & $\sin (p \pi \xi)$ & $\sin (l \pi \eta)$ \\
\hline & $\bar{W}(\xi, \eta)$ & $\sin ^{2}(p \pi \xi)$ & $\sin ^{2}(l \pi \eta)$ \\
\hline
\end{tabular}

It should be noted that approximating functions are provided for the case of an open asymmetrical structure. They can be applied, for example, for conical panels. In the case of symmetrical structure approximating functions are considered in [39]. 
We take into account (9), when differentiating $\tilde{\Phi}_{1}$ and $\tilde{\Phi}_{2}$.

Let us take variation of functional (8). The condition of its minimum is

$$
\delta \bar{I}=\delta_{U} \bar{I}+\delta_{V} \bar{I}+\delta_{W} \bar{I}=0
$$

that is, we obtain the system

$$
\begin{aligned}
\delta_{U} \bar{I} & =\sum_{i=1}^{N} \int_{\bar{t}_{0}}^{\bar{t}_{1}} \int_{0}^{1} \int_{0}^{1}\left[\frac{\partial \tilde{\Phi}_{1}}{\partial \dot{U}_{l}} \delta \dot{U}_{l}-\frac{\partial \tilde{\Phi}_{2}}{\partial U_{l}} \delta U_{l}\right] \bar{A} \bar{B} d \xi d \eta d \bar{t}=0, \\
\delta_{V} \bar{I} & =\sum_{i=1}^{N} \int_{\bar{t}_{0}}^{\bar{t}_{1}} \int_{0}^{1} \int_{0}^{1}\left[\frac{\partial \tilde{\Phi}_{1}}{\partial \dot{V}_{l}} \delta \dot{V}_{l}-\frac{\partial \tilde{\Phi}_{2}}{\partial V_{l}} \delta V_{l}\right] \bar{A} \bar{B} d \xi d \eta d \bar{t}=0, \\
\delta_{W} \bar{I} & =\sum_{i=1}^{N} \int_{\bar{t}_{0}}^{\bar{t}_{1}} \int_{0}^{1} \int_{0}^{1}\left[\frac{\partial \tilde{\Phi}_{1}}{\partial \dot{W}_{l}} \delta \dot{W}_{l}-\frac{\partial \tilde{\Phi}_{2}}{\partial W_{l}} \delta W_{l}\right] \bar{A} \bar{B} d \xi d \eta d \bar{t}=0, \quad l=1,2, \ldots, N .
\end{aligned}
$$

The sum sign used in (9) is factored out from the integral signs in relations (10). Moreover, unknown functions with both index $i$ and index $l$ are in $\tilde{\Phi}_{1}$ and $\tilde{\Phi}_{2}$. This is shown below in expanded form.

Upon integrating by parts and factoring out $\delta U_{l}, \delta V_{l}, \delta W_{l}$ from each equation, we obtain the equations of motion

$$
\begin{aligned}
& \sum_{i=1}^{N} \int_{0}^{1} \int_{0}^{1}\left[\frac{d}{d \bar{t}}\left(\frac{\partial \tilde{\Phi}_{1}}{\partial \dot{U}_{l}}\right)+\frac{\partial \tilde{\Phi}_{2}}{\partial U_{l}}\right] \bar{A} \bar{B} d \xi d \eta=0, \\
& \sum_{i=1}^{N} \int_{0}^{1} \int_{0}^{1}\left[\frac{d}{d \bar{t}}\left(\frac{\partial \tilde{\Phi}_{1}}{\partial \dot{V}_{l}}\right)+\frac{\partial \tilde{\Phi}_{2}}{\partial V_{l}}\right] \bar{A} \bar{B} d \xi d \eta=0, \\
& \sum_{i=1}^{N} \int_{0}^{1} \int_{0}^{1}\left[\frac{d}{d \bar{t}}\left(\frac{\partial \tilde{\Phi}_{1}}{\partial \dot{W}_{l}}\right)+\frac{\partial \tilde{\Phi}_{2}}{\partial W_{l}}\right] \bar{A} \bar{B} d \xi d \eta=0, \quad l=1,2, \ldots, N
\end{aligned}
$$

Now we can calculate integrals of known approximating functions with respect to $\xi, \eta$. Here $\sum_{i=1}^{N} \int_{0}^{1} \int_{0}^{1}\left[\frac{\partial \tilde{\Phi}_{2}}{\partial U_{l}}\right] \bar{A} \bar{B} d \xi d \eta, \quad \sum_{i=1}^{N} \int_{0}^{1} \int_{0}^{1}\left[\frac{\partial \tilde{\Phi}_{2}}{\partial V_{l}}\right] \bar{A} \bar{B} d \xi d \eta, \quad \sum_{i=1}^{N} \int_{0}^{1} \int_{0}^{1}\left[\frac{\partial \tilde{\Phi}_{2}}{\partial W_{l}}\right] \bar{A} \bar{B} d \xi d \eta$ are the left-hand sides of the equations of statics. They can be obtained with the use of the Ritz method applied to functional $\bar{E}_{p}[40]$ :

$$
\begin{gathered}
\sum_{i=1}^{N} \int_{0}^{1} \int_{0}^{1}\left[\frac{\partial \tilde{\Phi}_{2}}{\partial U_{l}}\right] \bar{A} \bar{B} d \xi d \eta=\sum_{i=1}^{N}\left[U_{i} C_{1}(i, l)+V_{i} C_{2}(i, l)+W_{i} C_{3}(i, l)\right]+\tilde{A}_{1}(l)=0, \\
\sum_{i=1}^{N} \int_{0}^{1} \int_{0}^{1}\left[\frac{\partial \tilde{\Phi}_{2}}{\partial V_{l}}\right] \bar{A} \bar{B} d \xi d \eta=\sum_{i=1}^{N}\left[U_{i} C_{6}(i, l)+V_{i} C_{7}(i, l)+W_{i} C_{8}(i, l)\right]+\tilde{A}_{2}(l)=0, \\
\sum_{i=1}^{N} \int_{0}^{1} \int_{0}^{1}\left[\frac{\partial \tilde{\Phi}_{2}}{\partial W_{l}}\right] \bar{A} \bar{B} d \xi d \eta=\sum_{i=1}^{N}\left[U_{i} C_{11}(i, l)+V_{i} C_{12}(i, l)+W_{i} C_{13}(i, l)\right]+\tilde{A}_{3}(l)- \\
-C_{P}(l) \bar{P}=0, \quad l=1,2, \ldots, N .
\end{gathered}
$$

Here $C_{1}, \ldots, C_{13}, C_{p}$ are coefficients, $\tilde{A}_{1}(l), \tilde{A}_{2}(l), \tilde{A}_{3}(l)$ are nonlinear terms of equations. 
The remaining terms of equation (10) are transformed as follows

$$
\begin{aligned}
& \sum_{i=1}^{N} \frac{\partial \tilde{\Phi}_{1}}{\partial \dot{U}_{l}}=\frac{1}{\bar{A}^{2}}\left[\left(1+\bar{F}_{p}\right) 2 \sum_{i=1}^{N} \dot{U}_{i} X 1(i) Y 1(i) \cdot X 1(l) Y 1(l)\right] \\
& \sum_{i=1}^{N} \frac{d}{d \bar{t}}\left(\frac{\partial \tilde{\Phi}_{1}}{\partial \dot{U}_{l}}\right)=\frac{2}{\bar{A}^{2}}\left[\left(1+\bar{F}_{p}\right) \sum_{i=1}^{N} \ddot{U}_{i} X 1(i) Y 1(i)\right] X 1(l) Y 1(l) \\
& \sum_{i=1}^{N} \int_{0}^{1} \int_{0}^{1}\left[\frac{d}{d \bar{t}}\left(\frac{\partial \tilde{\Phi}_{1}}{\partial \dot{U}_{l}}\right)\right] \bar{A} \bar{B} d \xi d \eta=\sum_{i=1}^{N}\left[\ddot{U}_{i} B 1(i, l)\right]
\end{aligned}
$$

After applying similar transformation to other equations of system (10), we obtain

$$
\begin{aligned}
& \sum_{i=1}^{N} \int_{0}^{1} \int_{0}^{1}\left[\frac{d}{d \bar{t}}\left(\frac{\partial \tilde{\Phi}_{1}}{\partial \dot{V}_{l}}\right)\right] \bar{A} \bar{B} d \xi d \eta=\sum_{i=1}^{N}\left[\ddot{V}_{i} B 3(i, l)\right] \\
& \sum_{i=1}^{N} \int_{0}^{1} \int_{0}^{1}\left[\frac{d}{d \bar{t}}\left(\frac{\partial \tilde{\Phi}_{1}}{\partial \dot{W}_{l}}\right)\right] \bar{A} \bar{B} d \xi d \eta=\sum_{i=1}^{N} \ddot{W}_{i} B 5(i, l)
\end{aligned}
$$

Here

$$
\begin{aligned}
& B 1(i, l)=\int_{0}^{1} \int_{0}^{1} \frac{2}{\bar{A}^{2}}\left(1+\bar{F}_{p}\right) X 1(i) Y 1(i) X 1(l) Y 1(l) \bar{A} \bar{B} d \xi d \eta \\
& B 3(i, l)=\int_{0}^{1} \int_{0}^{1} \frac{2 \bar{\lambda}^{2}}{\bar{A}^{2}}\left(1+\bar{F}_{p}\right) X 2(i) Y 2(i) X 2(l) Y 2(l) \bar{A} \bar{B} d \xi d \eta \\
& B 5(i, l)=\int_{0}^{1} \int_{0}^{1} 2\left(1+\bar{F}_{p}\right) X 3(i) Y 3(i) X 3(l) Y 3(l) \bar{A} \bar{B} d \xi d \eta
\end{aligned}
$$

Thus, the equations of motion of a stiffened orthotropic shell has the form

$$
\begin{aligned}
& \sum_{i=1}^{N}\left[\ddot{U}_{i} B 1(i, l)\right]+\Pi_{1}(l)=0, \\
& \sum_{i=1}^{N}\left[\ddot{V}_{i} B 3(i, l)\right]+\Pi_{2}(l)=0, \\
& \sum_{i=1}^{N} \ddot{W}_{i} B 5(i, l)+\Pi_{3}(l)=0, \quad l=1,2, \ldots, N,
\end{aligned}
$$

where $\Pi_{1}(l), \Pi_{2}(l), \Pi_{3}(l)$ are the left-hand sides of system (11).

Thus, the mathematical model of deformation of reinforced orthotropic shells is reduced to the initial value problem for a system of ordinary differential equations. Let us reduced system of ordinary differential equations (12) to the normal form. We introduce

$$
\dot{U}_{i}=\tilde{Y} 1_{i}, \quad \dot{V}_{i}=\tilde{Y} 2_{i}, \quad \dot{W}_{i}=\tilde{Y} 3_{i}
$$

Then system (12) can be written in the form

$$
\begin{aligned}
& \sum_{i=1}^{N}\left[\dot{\tilde{Y}} 1_{i} B 1(i, l)\right]+\Pi_{1}(l)=0, \\
& \sum_{i=1}^{N}\left[\dot{\tilde{Y}} 2_{i} B 3(i, l)\right]+\Pi_{2}(l)=0, \\
& \sum_{i=1}^{N} \dot{\tilde{Y}} 3_{i} B 5(i, l)+\Pi_{3}(l)=0, \quad l=1,2, \ldots, N .
\end{aligned}
$$


The matrix of coefficients of system (13) can be schematically represented in the form

$$
\mathrm{B}=\left(\begin{array}{ccc}
B 1 & 0 & 0 \\
0 & B 3 & 0 \\
0 & 0 & B 5
\end{array}\right)
$$

The dimension of this matrix is $3 N \times 3 N$. Now system (13) can be written as

$$
\mathrm{B} \dot{Y}(t)=\Pi(t, X)
$$

where $\dot{Y}(t)=(\dot{\tilde{Y}} 1, \dot{\tilde{Y}} 2, \dot{\tilde{Y}} 3)^{T}, \Pi=\left(-\Pi_{1}(l),-\Pi_{2}(l),-\Pi_{3}(l)\right)^{T}, \quad X=\left(U_{i}, V_{i}, W_{i}\right)^{T}, l=$ $1, \ldots, N, i=1, \ldots, N$.

Matrix $\Pi$ is the column matrix of the right-hand sides of system (6). Let us find the inverse of matrix B. Each element of the matrix B is known. Then we obtain

$$
\mathrm{B}^{-1} \mathrm{~B} \dot{Y}(t)=\mathrm{B}^{-1} \Pi(t, X)=F(t, X) .
$$

Thus we have a normal system of ordinary differential equations

$$
\dot{Y}(t)=F(t, X), \quad \dot{U}_{i}=\tilde{Y} 1_{i}, \quad \dot{V}_{i}=\tilde{Y} 2_{i}, \quad \dot{W}_{i}=\tilde{Y} 3_{i}, \quad i=1, \ldots, N,
$$

which can be represented in the form $\dot{X}(t)=Y(t)$.

This system is solved with the initial conditions at $t=0$

$$
U_{i}=V_{i}=W_{i}=0, \quad \dot{U}_{i}=\dot{V}_{i}=\dot{W}_{i}=0, \quad i=1, \ldots, N
$$

Coefficients of the matrix B and coefficients in the expressions for $\Pi$ are obtained with the use of boundary conditions. In what follows we assume that $q=A \cdot t$.

Upon substituting initial conditions (14) into the column matrix $\Pi$ with $3 N$ elements, $N$ elements of the matrix are not equal to zero. This is due to the presence of a load term that depends on $t$.

To solve the initial value problem for systems of ordinary differential equations (11), (12) various numerical methods can be used. Since they are stiff systems one can use, for example, an implicit Runge-Kutta scheme.

\section{Numerical results}

The initial value problem for the ODE system is solved with the use of computing software Maple 2015. The system is numerically solved using an implicit Runge-Kutta scheme.

As an example, we consider a shallow shell of double curvature $\left(A=B=1, k_{x}=k_{y}=1 / R\right)$. The contour of the shell is simply supported. The shell is subjected to the dynamic external uniformly distributed lateral load $q=q(x, y, t)=100 t$. The dimensional parameters of the shell are $a=b=60 h, R_{1}=R_{2}=225 h, h=0.09 \mathrm{~m}$. The shell is made of steel with the modulus of elasticity $E=2.1 \cdot 10^{5} \mathrm{MPa}$ and Poisson ratio $\mu=0.3$. The system is solved in terms of dimensionless parameters and $N=9$.

Fig. 1 shows the relationship between load $\bar{P}$ and displacement $\bar{W}_{c}$ at the center of the shell.

An inflection point on the curve "load-displacement" is the point of stability loss under dynamic loading. Such criterion was proposed by A. S. Vol'mir. It is seen from Fig. 1 that after buckling load $\bar{P}=232$ shell oscillates around the equilibrium state of the static problem. 


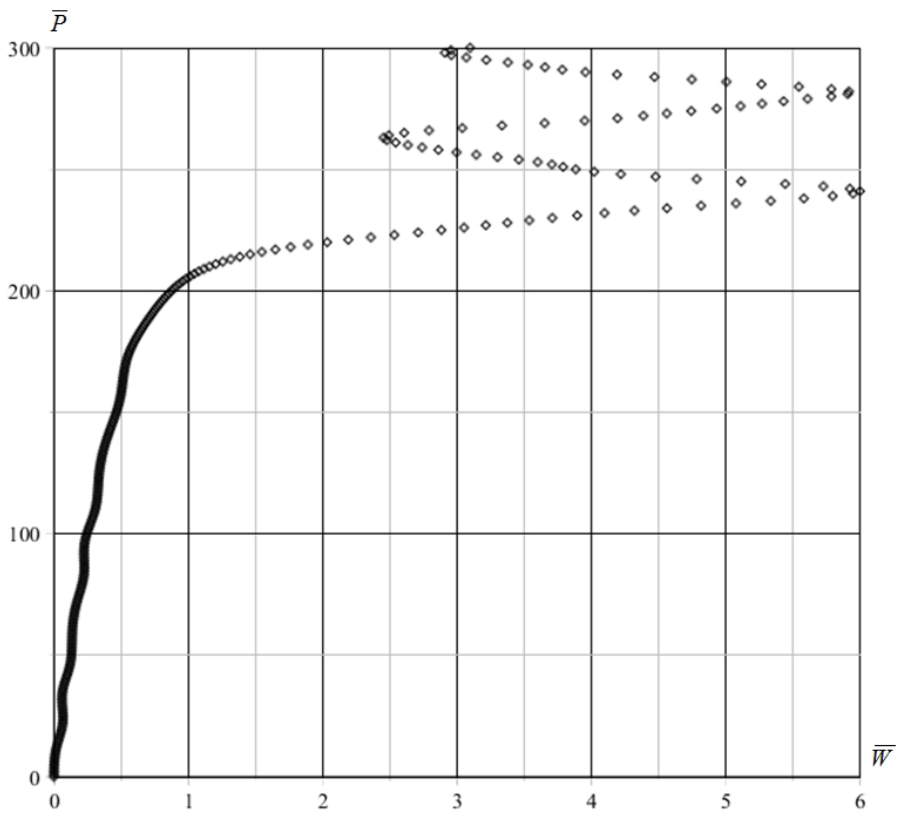

Fig. 1. Relationship between load $\bar{P}$ and displacement $\bar{W}_{c}$ at the center of the shell

\section{Conclusions}

The mathematical model of the deformation of stiffened orthotropic shells under dynamic loading was presented. The model is represented in the form of an initial value problem for a system of ordinary differential equations that is easier to solve than the system of equations of motion in partial derivatives. The proposed model takes into account the geometric nonlinearity, and can be applied to orthotropic materials. Stiffeners can be introduced as discrete elements or with the use of the method of constructive anisotropy.

The work was supported by the Ministry of Education and Science of the Russian Federation (project 3801).

\section{References}

[1] H.Abramovich, V.A.Zarutskii, Stability and vibrations of nonclosed circular cylindrical shells reinforced with discrete longitudinal ribs, Int. Appl. Mech., 44(2008), no. 1, 16-22.

[2] V.F.Meish, A.S.Kairov, Vibrations of reinforced cylindrical shells with initial deflections under nonstationary loads, Int. Appl. Mech., 41(2005), no. 1, 42-48.

[3] N.A.Shul'ga, S.Yu.Bogdanov, Forced axisymmetric nonlinear vibrations of reinforced conical shells, Int. Appl. Mech., 39(2003), no. 12, 1447-1451.

[4] S.G.Suleymanova, Free vibrations of a filled cylindrical shell longitudinally strengthened and loaded with axial contracting forces, Proc. of IMM of Azer., XXVII(2007), 135-140. 
[5] G.I.Belikov, S.Yu.Kalashnikov, Layout operation of stiffened cylindrical shells of the bridge conduits under free oscillations, Bulleten Volgograd. Gos Univ. Arhitectury i Grazhd. Enginer. Ser.: Civ. Eng. and Arch., (2011), no. 25(44), 14-20 (in Russian).

[6] Yu.P.Dyachenko, E.J.Elenitskiy, D.V.Petrov, Non-stationary problems of the dynamics of stepped section plates and rotation cylindrical shells, Vestn. Samar. Gos. Tekhn. Univ. Ser. Fiz.-Mat. Nauki, (2011), no. 2(23), 278-288 (in Russian).

[7] F.S.Latifov, S.G.Suleymanova, A problem of free vibrations medium-filled cylindrical shells reinforced by a cross system of ribs and loaded with axial contracting forces, Mehanika mashin, mehanizmov i materialov, (2009), no. 1, 59-61 (in Russian).

[8] M.A.Mehtiyev, Nonlinear parametric vibrations of stiffened cylindrical shell with a viscoelastic filler, Mehanika mashin, mehanizmov i materialov, (2011), no. 3(16), 28-30 (in Russian).

[9] N.A.Nazarov, Oscillations of shallow shells, reinforced by stiffening ribs, Applied Mechanics, $\mathbf{1}(1965)$, no. $3,24-31$

[10] Yu.I.Nemchinov, Yu.A.Talbatov, Free oscillations of shallow cylindrical shells reinforced by stiffening ribs, Struct. Mehan. i Anal. Konst., (1975), no. 3, 17-22 (in Russian).

[11] A.I.Seyfullayev, K.A.Novruzova, Oscillations of a longitudinally reinforced orthotropic cylindrical shell filled with a viscous fluid, Eastern-European Journal of Enterprise Technologies, (2015), no. 3/7(75), 29-33 (in Russian).

[12] G.V.Tertishniy, Effect of stiffeners on the frequency of free oscillations of a shallow cylindrical panel, Bulleten Kazan. Tehnolog. Universiteta, (2011), no. 19, 217-224 (in Russian).

[13] E.A.Kogan, A.A.Yurchenko, Nonlinear oscillations of a three-layer and multi-layer plates and shells during periodic impacts (survey), Izvestiya MGTU MAMI. Seriya estestv. nayk, 4(2014), no. 1(19), 55-70 (in Russian).

[14] V.D.Kubenko, P.S.Koval'chuk, Nonlinear problems of the dynamics of elastic shells partially filled with a liquid, Int. Appl. Mech., 36(2000), 421-448.

[15] V.D.Kubenko, P.S.Koval'chuk, Nonlinear problems of the vibration of thin shells (review), Int. Appl. Mech., 34(1998), no. 8, 703-728.

[16] M.Amabili, M.P.Païdoussis, Review of studies on geometrically nonlinear vibrations and dynamics of circular cylindrical shells and panels, with and without fluid-structure interaction, Appl. Mech. Rev., 56(2003), 349-381.

[17] F.Moussaoui, R.Benamar, Non-linear vibrations of shell-type structures: a review with bibliography, Journal of Sound and Vibration, 255(2002), 161-184.

[18] M.S.Qatu, R.W.Sullivan, W.Wang, Recent research advances on the dynamic analysis of composite shells: 2000-2009 (Review), Composite Structures, 93(2010), 14-31.

[19] S.K.Sahu, P.K.Datta, Research advances in the dynamic stability behavior of plates and shells: 1987-2005 - part I: conservative systems, Appl. Mech. Rev., 60(2007), no. 2, 60-65. 
[20] N.A.Abrosimov, V.G.Bazhenov, Nonlinear problems of composite structural dynamics, Nizhni Novgorod, Izd. NNGU, 2002 (in Russian).

[21] I.Ya.Amiro, V.A.Zarutskii, V.G.Palamarchuk, Dynamics of ribbed shells, Kiev, Naukova dumka, 1983 (in Russian).

[22] Y.Kimihiko, Review of research in Japan on nonlinear oscillations of elastic structures, ISME Int. Journ. C., 39(1996), no. 3, 439-449.

[23] A.N.Blinov, On the Lower Critical Load of the Elastic Cylindrical Shell with Axial Compression, Journal of Siberian Federal University. Mathematics and Physics, 5(2012), no. 3, 359-362 (in Russian).

[24] T.Ueda, Non-linear free vibrations of conical shells, Journal of Sound and Vibration, 64(1979), no. 1, 85-95.

[25] M.Amabili, R.Garziera, R.Muharlyamov, K.Ryabova, Nonlinear oscillations of shallow shells of double curvature, Vestnik Kazanskogo Technolog. Universiteta, 18(2015), no. 6, 158-162 (in Russian).

[26] V.M.Dubrovin, T.A.Butina, Modeling of the dynamic stability of a cylindrical shell under the axial compressive load, Mat. Mod. Chisl. Met., (2015), no. 2(6), 46-57 (in Russian).

[27] G.I.Kolosov, Vibration and Secular Instability of Equilibrium States of Cylindrical Shells under Axial Compression, Cosmonavtika i Raketostroenie, (2012), no. 2(67), 145-150. (in Russian)

[28] V.V.Platonov, The stability of the transversely isotropic spherical shell under the normal dynamic loading, Vestnik St.-Petersburg Univ. Ser.1, (2010), no. 3, 105-110 (in Russian).

[29] L.Yu.Stupishin, A.G.Kolesnikov, I.V.Solomatnikov, Geometric nonlinear shallow shells optimum forms examination for maximum lowest frequencies of small free oscillations, Trudy Yugo-Zapadn. Gos. Univer., (2011), no. 5-2, 313-316 (in Russian).

[30] N.A.Taranuha, G.S.Leyzerovich, Non-linear free flexural oscillations thin circle cylindrical shells, Far Eastern Mathematical Journal, (2000), no. 1, 102-110 (in Russian)

[31] W.W.Bendukov, W.W.Derushev, M.M.Lurie, P.N.Owcharov, About influence of filler on critical parameters of an impulse of pressure at dynamic loss of stability of a cylindrical envelope, Nauchn. bulleten Moskov. Gos. Tehnich. Univer. Grazhdan. Aviatsii, (2005), no. 84(2), 131-137 (in Russian)

[32] A.V.Krysko, V.A.Krysko, N.E.Saveleva, Chaotic vibrations of closed cylindrical shells and plates. Part I, Vestnik SSTU, (2005), no. 3(8), 32-61 (in Russian).

[33] D.Li, A time-mode approach to nonlinear vibrations of orthotropic thin shallow spherical shells, Int. J. Solids Structures, 30(1993), no. 22, 3113-3128.

[34] V.A.Krysko, I.V.Kravtsova, Dynamics and statistics of sectorial shells, Vestnik SSTU, (2004), no. 2(3), 27-36 (in Russian). 
[35] V.V.Karpov, O.V.Ignat'ev, A.Yu.Salnikov, Nonlinear mathematical models of deformation of shells of variable thickness and algorithms for their research, Moscow, ASV; SPb, SPbSUACE, 2002 (in Russian).

[36] A.S.Vol'mir, Nonlinear dynamics of plates and shells, Moscow, Nauka, 1972 (in Russian).

[37] L.V.Kantorovich, A direct method for the approximate solution of problem of the minimum of a double integral, Trudy Akad. Nauk SSSR, Matematich. i estest. nauki, (1933), no. 5, 647-652 (in Russian)

[38] V.V.Karpov, A.A.Semenov, Dimensionless parameters in the theory of reinforced shells, PNRPU Mehanika Bulleten, (2015), no. 3, 74-94 (in Russian)

[39] V.V.Karpov, The strength and stability of reinforced shells of revolution. In two parts. Part 1. Models and algorithms of research of the strength and stability of supported shells of revolution, Moscow, Fizmatlit, 2010 (in Russian).

[40] A.A.Semenov, Algorithms for the research of strength and stability of reinforced orthotropic shells, Struct. Meh. Eng. Konst. i Sroit., (2014), no. 1, 49-63 (in Russian).

\section{Математические модели деформирования подкрепленных ортотропных оболочек при динамическом нагружении}

Алексей А. Семенов

Санкт-Петербургский государственный архитектурно-строительный университет 2-я Красноармейская, 4, Санкт-Петербург, 190005

Россия

В данной работе рассматриваются два варианта математической модели деформирования подкрепленных ортотропных оболочек при динамическом нагружении: в виде уравнений движения и в виде системы обыкновенных дифберенциалъных уравнений. Математические модели строятся на основе гипотез теории оболочек Кирхгофа-Лява, учитывают геометрическую нелинейность и ортотропию материала, а также возможность наличия подкрепления конструкиии. Все соотношения моделей даются в общем виде и при указании соответствующих параметров Ляме могут быть использованы для широкого класса различных конструкиий (пологих оболочек двоякой кривизны, иилиндрических, конических, сферических и тороидалъных оболочек и их панелей и др.). Важной особенностью предложенной модели является возможность введения ребер жесткости как дискретно, так и по методу конструктивной анизотропии с учетом их сдвиговой и крутильной жесткости. Второй вариант математической модели выводится путем применения $к$ бункиионалу полной энергии дебормации оболочки метода Л. В. Канторовича (метод сведения трехмерного бункиионала $к$ одномерному). Полученная началъная задача решается существенно проще, чем система уравнений движения в частных производных.

Ключевые слова: математическая модель, оболочки, динамическое нагружение, ортотропия, геометрическая нелинейность, уравнения двиюения, метод конструктивной анизотропии. 